\title{
Gas Chromatography-Triple Quadrupole Mass Spectrometry Analysis of Dioxins in Soil
}

\author{
Young Sang Kwon, Sung-Gil Choi, Seung-Min Lee, Jong-Hwan Kim and Jong-Su Seo* \\ Environmental Toxicology Research Center, Korea Institute of Toxicology, Jinju 52834, Korea
}

Received: 06 Dec 2017; accepted: 27 Feb 2018

\begin{abstract}
The applicability of gas chromatography-triple quadrupole mass spectrometry (GC-MS/MS) for determination of dioxins in soil was investigated. The analytical method was validated based on US Environmental Protection Agency (EPA) Method 1613 and European Union (EU) Regulation No. 709/2014 for selectivity, linearity of sensitivity, and instrumental limits of quantification (iLOQs). Method development commenced with determination of retention times for 17 native polychlorinated dibenzo-p-dioxins (PCDDs) and polychlorinated dibenzofurans (PCDFs) and selection of characteristic ions from GC-MS/MS spectra. The linearity was measured using 1613 standard solutions (CS1-CS5) containing 0.5 to $200 \mathrm{ng} / \mathrm{mL}$ tetrachlorodibenzo-p-dioxin/furan (TCDD/F) congeners, 2.5 to $1000 \mathrm{ng} / \mathrm{mL}$ pentachlorodibenzo-p-dioxin/furan (PeCDD/F) to heptachlorodibenzo-p-dioxin/furan (HpCDD/F) congeners, and 20 to $2000 \mathrm{ng} / \mathrm{mL}$ octachlorodibenzo-p-dioxin/furan (OCDD/F) congeners. The correlation coefficient $\left(R^{2}\right)$ values ranged between 0.9990 and 0.9999 , and the iLOQ values ranged from 0.052 to 0.350 $\mathrm{pg} / \mu \mathrm{L}$ for $\mathrm{TCDD} / \mathrm{F}$ congeners, with a relative standard deviation of $2.7-9.6 \%$. The entire analytical method was verified by analysis of certified reference materials (BCR-529 and BCR-530), and the recoveries were 71.79$103.87 \%$ and $81.50-103.12 \%$, respectively. Thus, the GC-MS/MS system provides an alternative to GC-high-resolution MS for the simultaneous determination of TCDD/F congeners in soil.
\end{abstract}

Keywords: dioxins, GC-MS/MS, polychlorinated dibenzo-p-dioxins, polychlorinated dibenzofurans, soil analysis

\section{Introduction}

Polychlorinated dibenzo-p-dioxins (PCDDs) and polychlorinated dibenzofurans (PCDFs) are important environmental pollutants (also known as dioxins) that are classified as persistent organic pollutants (POPs) and lead to a broad range of toxic effects in humans and natural environments [1-3]. PCDD/PCDFs are unintentionally formed as by-products during a variety of industrial, manufacturing, and combustion processes [4-8]. Dioxins are chemically highly stable and persist in environmental ecosystems for many years due to a halflife in soil of 10-12 years [9]. For this reason, analytical methods for the determination of dioxins in natural environments are being actively developed.

For instrumental determination, exhaustive extraction, extensive clean-up and sensitive detection procedures are required to determine dioxins in complex matrices. Highresolution gas chromatography coupled to high-resolution mass spectrometry (HRGC/HRMS) is a powerful tool for dioxin research, which has been used successfully for analysis of $\mathrm{PCDD} / \mathrm{F}$ congeners, and designated as an international reference method [10-15]. HRGC/HRMS has advantages and disadvantages in terms of the analysis process and equipment. Advantages include its high sensitivity, high selectivity, and robustness in terms of MS [16-17]. Disadvantages include its relatively high cost and difficult usage [18]. For these reasons, the development of alternative methods that are more reliable than HRMS but with similar or better reliability is ongoing.

\footnotetext{
* Author for correspondence: Environmental Toxicology Research Center, Korea Institute of Toxicology, Jinju 52834, Korea; E-mail: jsseo@kitox.re.kr; Tel: +82-55-750-3750; Fax: +82-55-750-3768.
}

As an alternative to HRGC/HRMS, gas chromatographytriple quadrupole mass spectrometry (GC-MS/MS) should in theory be able to determine dioxin congeners at very low concentrations, potentially providing unambiguous evidence to confirm measurements derived from HRGC/HRMS. Accuracy and sensitivity have both been recently improved due to technological and developmental advances in mass spectrometry (MS). These improvements are in accordance with the analytical criteria of HRGC/HRMS and represent enhanced selectivity. In recent years, analysis of dioxins from matrices including food, feed, fats, sewage sludge, and fly ash samples using GC-MS/MS have revealed sensitivity and accuracy comparable with HRGC/HRMS [15, 18-23]. Therefore, GC$\mathrm{MS} / \mathrm{MS}$ could, in principle, be employed for analysis of POPs, such as dioxins, and for analysis of harmful and toxic substances in various fields.

To the best of our knowledge, determination of dioxin congeners in soil using GC-MS/MS instead of HRGC/HRMS has not been reported previously. In the present study, we demonstrate the applicability of the GC-MS/MS system for analysis of $\mathrm{PCDD} / \mathrm{F}$ congeners in soil containing low levels of these compounds.

\section{Experimental}

Reagents, Standards, and Materials. All reagents and solvents for dioxin analysis were of analytical grade or HPLC-grade. Toluene and nonane of dioxin analysis grade were provided by Wako Pure Chemical Industries (Tokyo, Japan), and other solvents including dichloromethane, hexane, and methanol $(\mathrm{MeOH})$ were obtained from Burdick \& Jackson (Muskegon, MI, USA). A multilayer silica gel column $(10 \%$ silver nitrate silica gel, $44 \%$ sulfuric silica gel,

This is an open-access article distributed under the terms of the Creative Commons Attribution-NonCommercial 4.0 International License (https://creativecommons.org/licenses/by-nc/4.0/), which permits unrestricted use, distribution, and reproduction in any medium for non-commercial purposes, provided the original author and source are credited, a link to the CC License is provided, and changes - if any - are indicated. 


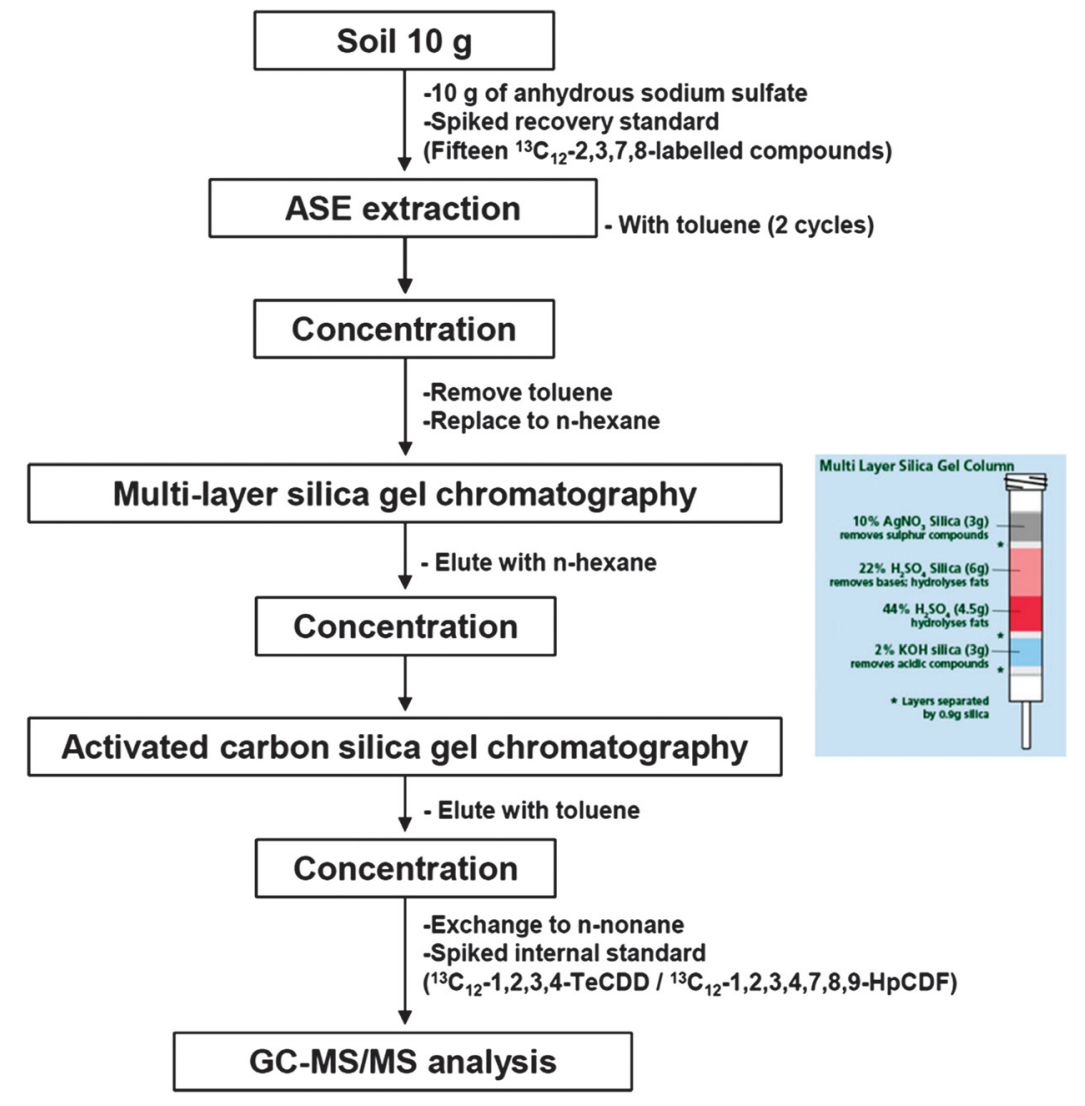

Figure 1. Flow diagram of the sample extraction and clean-up procedures

$22 \%$ sulfuric silica gel, and $2 \%$ potassium hydroxide silica gel) and activated carbon solid phase extraction (SPE) cartridges were obtained from GL Science Inc. (Tokyo, Japan) and Sigma-Aldrich (St. Louis, MO, USA). Native and ${ }^{13} \mathrm{C}_{12^{-}}$ isotope-labelled standard mixtures of PCDD/Fs (EPA 1613 CS1 to CS5, LCS, and ISS) were certified purchases from Wellington Laboratories Inc. (Guelph, Ontario, Canada) and were used for the development of the analytical methodology. Certified reference material (CRM) samples including BCR 529 (sandy soil) and 530 (clay soil) were obtained from the Institute for Reference Materials and Measurements (IRMM, Geel, Belgium) for method validation.

Sample Extraction and Clean-up. Extraction procedures for determination of dioxins in soil were performed as described previously [24] with a slight modification, as shown in Figure 1. Briefly, $10 \mathrm{~g}$ soil was spiked with ${ }^{13} \mathrm{C}$-labelled compounds (EPA 1613 LCS) as internal (surrogate) standards, and extraction was performed using an ASE 300 system (Dionex, Sunnyvale, CA, USA) with instrument settings as follows: $170{ }^{\circ} \mathrm{C}, 1500 \mathrm{psi}, 70 \%$ flush volume, 2 static cycles of $6 \mathrm{~min}$, and toluene as an extraction solvent. The aliquots were evaporated by rotary evaporation, solvent was replaced with $n$-hexane, and samples were injected into a multilayer silica gel column pre-equilibrated with $25 \mathrm{~mL} n$-hexane. After elution of $100 \mathrm{~mL} n$-hexane and evaporation to dryness, the samples were redissolved in $3 \mathrm{~mL} n$-hexane and transferred to an active carbon SPE column to separate PCDD/Fs. The activated carbon SPE column was washed with $50 \mathrm{~mL}$ DCMhexane $(1: 1, v / v)$ to separate the interfering material and eluted with $100 \mathrm{~mL}$ toluene. The eluted extract was evaporated to dryness using nitrogen gas, redissolved in $25 \mu \mathrm{L}$ nonane, and EPA1613 ISS $\left({ }^{13} \mathrm{C}_{12}-1,2,3,4-\right.$ tetrachlorodibenzo-p-dioxin [TCDD] and ${ }^{13} \mathrm{C}_{12}-1,2,3,7,8,9$-hexachlorodibenzo-p-dioxin [HxCDD]) were added as an internal injection standard at a final concentration of $100 \mathrm{ng} / \mathrm{mL}$. The samples were transferred to auto-sampling vials and analyzed by GC-MS/ MS.

Instrumental Analysis (GC-MS/MS). For determination of $\mathrm{PCDD} / \mathrm{F}$ congeners, we used a Bruker Scion TQ triple quadruple mass spectrometer (Bruker, Fremont, CA, USA) coupled to a Bruker $451 \mathrm{GC}$ and CP 8400 auto sampler, with a DB-5MS UI capillary column $(60 \mathrm{~m} \times 0.25 \mathrm{~mm} \times 0.25 \mu \mathrm{m}$; J\&W Scientific, Folsom, CA, USA) operated in the selected ion monitoring (SIM) mode and the electron ionization (EI) positive mode at $70 \mathrm{eV}$. The temperatures of the transfer line, injector, and ion source were $280^{\circ} \mathrm{C}$ and $230{ }^{\circ} \mathrm{C}$, respectively. For analysis, a $2-\mu \mathrm{L}$ sample was injected in the pulse splitless mode. Helium at a constant flow rate of $1 \mathrm{~mL} / \mathrm{min}$ was used as the carrier gas. The program temperature was $140{ }^{\circ} \mathrm{C}$ for $1 \mathrm{~min}$, increased to $220^{\circ} \mathrm{C}$ at $20^{\circ} \mathrm{C} / \mathrm{min}$ (held for $1 \mathrm{~min}$ ) and then to $320^{\circ} \mathrm{C}$ at $5{ }^{\circ} \mathrm{C} / \mathrm{min}$ (held for $14 \mathrm{~min}$ ) for a total runtime of $35 \mathrm{~min}$. Details of the GC-MS/MS operational parameters, as well as the multiple reaction monitoring (MRM) conditions for PCDD/Fs determination, are provided in Tables 1 and 2.

\section{Results and Discussion}

Analytical Validation of the GC-MS/MS Method. Analytical performance was assessed in terms of selectivity, linearity of sensitivity, and instrumental limits of quantification (iLOQs) according to the validation parameters for GC-MS/MS method development. EPA-1613 CS3 calibration standard solutions were selected to evaluate the chromatographic separation of PCDD/Fs, and the separation was acceptable for all PCDD/F congeners (Figure 2). Optimization of operational parameters was performed by selecting the two most abundant precursor ions for each target compound from full scan spectra of PCDD/Fs. Tables 2 summarizes the MRM transitions and optimum collision energy (CE) voltages for each congener and transition. 
Table 1. Experimental conditions for gas chromatography-triple quadrupole mass spectrometry (GC-MS/MS) analysis of polychlorinated dibenzo-p-dioxins (PCDDs) and polychlorinated dibenzofurans (PCDFs)

\section{GC conditions}

\begin{tabular}{lc}
\hline Column & DB-5MS UI \\
& $60 \mathrm{~m} \times 250 \mathrm{~mm} \times 0.25 \mu \mathrm{m}$ \\
$\begin{array}{l}\text { Injection volume } \\
(\mu \mathrm{L})\end{array}$ & 2.0, splitless \\
$\begin{array}{l}\text { Inlet temp. }\left({ }^{\circ} \mathrm{C}\right) \\
\text { Inlet module } \\
\text { and mode }\end{array}$ & 280 \\
Carrier gas & Pulsed splitless, $50 \mathrm{psi}(1 \mathrm{~min})$ \\
Column flow & \\
(mL/min) & Helium \\
Column pneumatics & 1.0 \\
Oven program & Constant flow \\
& $140{ }^{\circ} \mathrm{C}(1 \mathrm{~min})$ \\
& $20{ }^{\circ} \mathrm{C} / \mathrm{min}$ to $220^{\circ} \mathrm{C}(1 \mathrm{~min})$
\end{tabular}

MS conditions

Operation mode

MS system

Transfer line

temperature

Ion source

temperature

Electron energy

Collision gas

Linearity is an important factor determining the accuracy of the analytical validation process. Linearity tests were optimized and applied to five calibration standard solutions (EPA1613 CS1 to CS5) including native and ${ }^{13} \mathrm{C}_{12}$-labelled tetrachlorodibenzo$\mathrm{p}$-dioxin/furan $(\mathrm{TCDD} / \mathrm{F})$ congeners at concentrations ranging from 0.5 to $2000 \mathrm{pg} / \mu \mathrm{L}$ and $100 \mathrm{pg} / \mu \mathrm{L}$, respectively, except for ${ }^{13} \mathrm{C}_{12}$-octachlorodibenzo-p-dioxin (OCDD), which was $200 \mathrm{pg} /$ $\mu \mathrm{L}$. Determination coefficient $\left(R^{2}\right)$ values higher than 0.999 indicated good linearity, and the relative response factor (RRF) and relative standard deviation (RSD) values were in good agreement $(\mathrm{RSD}<15 \%$ ) for PCDD/F congeners (Table 3 ). These excellent linearity results confirmed that method was in accordance with the criteria established earlier by the EPA 1613 method.

One of the major differences between HRGC/HRMS and GC-MS/MS is the ability to set the iLOQ value; although HRGC/HRMS is measured by the signal-to-noise $(S / N)$ ratio for raw signals, GC-MS/MS does not allow calculation of the $S / N$ ratio due to filtering of ions by the quadrupoles [25]. For these reasons, iLOQ values for the GC-MS/MS system were measured using a 10-fold dilution of the EPA-1613CS1 standard solution following 10 repeated injections, which were considered to be 10 times the RSD of the replicates. The iLOQ values ranged from 0.052 to $0.350 \mathrm{pg} / \mu \mathrm{L}$ for TCDD/F congeners. All \%RSD values were below 9.6\% (Table 4), suggesting that the proposed GC-MS/MS analytical method was sufficiently sensitive to easily detect low-level dioxin congeners.

Determination of Dioxins in CRMs. To assess the accuracy of the validation tests used to assess the analytical method, we evaluated the analytical efficiency using two CRMs, BCR 529 and 530, which are the same matrices as the real samples. The accuracy values obtained as recovery factors for dioxin congeners were used as reference values for quality assurance with the GC-MS/MS instrument. CRM and accuracy results are shown in Table 5. The measured total dioxin values for BCR $529\left(16,865.53\right.$ pg. $\left.\mathrm{g}^{-1}\right)$ and BCR 530 (1495.69 pg. $\mathrm{g}^{-1}$ ) were in good agreement with the certified values for BCR $529(20,025 \pm 2981 \mathrm{pg} / \mathrm{g})$ and BCR 530 $(1575 \pm 174 \mathrm{pg} / \mathrm{g})$. The range of accuracy of values for dioxin congeners compared with certified values for BCR 529 and BCR 530 were $71.79-103.87 \%$ (average $=84 \%$ ) and 81.50

Table 2. Multiple reaction monitoring (MRM) conditions for detection of the PCDD/F congeners

\begin{tabular}{|c|c|c|c|c|c|c|c|}
\hline Congeners & RT (min) & Precursor ion & Product ion & CE (V) & Precursor ion & Product ion & $\mathrm{CE}(\mathrm{V})$ \\
\hline${ }^{13} \mathrm{C}-2,3,7,8-\mathrm{TCDF}$ & 15.40 & 316 & 252 & 30 & 318 & 254 & 30 \\
\hline $2,3,7,8-\mathrm{TCDF}$ & 15.41 & 304 & 241 & 30 & 306 & 243 & 30 \\
\hline${ }^{13} \mathrm{C}-1,2,3,4-\mathrm{TCDD}\left(\mathrm{ISS}^{*}\right)$ & 15.46 & 332 & 268 & 22 & 334 & 270 & 22 \\
\hline $2,3,7,8-\mathrm{TCDD}$ & 15.71 & 320 & 257 & 22 & 322 & 259 & 22 \\
\hline${ }^{13} \mathrm{C}-1,2,3,7,8-\mathrm{PeCDF}$ & 17.62 & 350 & 286 & 32 & 352 & 288 & 32 \\
\hline $1,2,3,7,8-\mathrm{PeCDF}$ & 17.63 & 338 & 275 & 30 & 340 & 277 & 30 \\
\hline${ }^{13} \mathrm{C}-2,3,4,7,8-\mathrm{PeCDF}$ & 18.18 & 350 & 286 & 32 & 352 & 288 & 32 \\
\hline $2,3,4,7,8-\mathrm{PeCDF}$ & 18.21 & 338 & 275 & 30 & 340 & 277 & 30 \\
\hline${ }^{13} \mathrm{C}-1,2,3,7,8-\mathrm{PeCDD}$ & 18.36 & 368 & 304 & 22 & 370 & 306 & 22 \\
\hline $1,2,3,7,8-\mathrm{PeCDD}$ & 18.38 & 354 & 291 & 25 & 356 & 293 & 25 \\
\hline${ }^{13} \mathrm{C}-1,2,3,4,7,8-\mathrm{HxCDF}$ & 20.22 & 386 & 322 & 32 & 388 & 324 & 32 \\
\hline $1,2,3,4,7,8-\mathrm{HxCDF}$ & 20.24 & 374 & 311 & 30 & 376 & 313 & 30 \\
\hline${ }^{13} \mathrm{C}-1,2,3,6,7,8-\mathrm{HxCDF}$ & 20.33 & 386 & 322 & 32 & 388 & 324 & 32 \\
\hline $1,2,3,6,7,8-\mathrm{HxCDF}$ & 20.34 & 374 & 311 & 30 & 376 & 313 & 30 \\
\hline${ }^{13} \mathrm{C}-2,3,4,6,7,8-\mathrm{HxCDF}$ & 20.76 & 386 & 322 & 32 & 388 & 324 & 32 \\
\hline $2,3,4,6,7,8-\mathrm{HxCDF}$ & 20.77 & 374 & 311 & 30 & 376 & 313 & 30 \\
\hline $1,2,3,4,7,8-\mathrm{HxCDD}$ & 20.85 & 388 & 262 & 40 & 390 & 327 & 25 \\
\hline${ }^{13} \mathrm{C}-1,2,3,6,7,8-\mathrm{HxCDD}$ & 21.14 & 402 & 338 & 22 & 404 & 340 & 22 \\
\hline $1,2,3,6,7,8-\mathrm{HxCDD}$ & 21.16 & 388 & 262 & 40 & 390 & 327 & 25 \\
\hline${ }^{13} \mathrm{C}-1,2,3,7,8,9-\mathrm{HxCDD}\left(\mathrm{ISS}^{*}\right.$ ) & 21.13 & 402 & 338 & 22 & 404 & 340 & 22 \\
\hline $1,2,3,7,8,9-\mathrm{HxCDD}$ & 21.16 & 388 & 262 & 40 & 390 & 327 & 25 \\
\hline${ }^{13} \mathrm{C}-1,2,3,7,8,9-\mathrm{HxCDF}$ & 21.48 & 386 & 322 & 32 & 388 & 324 & 32 \\
\hline $1,2,3,7,8,9-\mathrm{HxCDF}$ & 21.48 & 374 & 311 & 30 & 376 & 313 & 30 \\
\hline${ }^{13} \mathrm{C}-1,2,3,4,6,7,8-\mathrm{HpCDF}$ & 22.61 & 420 & 356 & 35 & 420 & 358 & 35 \\
\hline $1,2,3,4,6,7,8-\mathrm{HpCDF}$ & 22.60 & 408 & 345 & 35 & 410 & 347 & 35 \\
\hline${ }^{13} \mathrm{C}-1,2,3,4,6,7,8-\mathrm{HpCDD}$ & 23.46 & 436 & 372 & 22 & 438 & 374 & 22 \\
\hline $1,2,3,4,6,7,8-\mathrm{HpCDD}$ & 23.48 & 424 & 361 & 25 & 426 & 363 & 25 \\
\hline${ }^{13} \mathrm{C}-1,2,3,4,7,8,9-\mathrm{HpCDF}$ & 23.94 & 420 & 356 & 35 & 422 & 358 & 35 \\
\hline $1,2,3,4,7,8,9-\mathrm{HpCDF}$ & 23.96 & 408 & 345 & 35 & 410 & 347 & 35 \\
\hline${ }^{13} \mathrm{C}-\mathrm{OCDD}$ & 25.87 & 470 & 406 & 25 & 472 & 408 & 25 \\
\hline OCDD & 25.87 & 458 & 395 & 25 & 460 & 397 & 25 \\
\hline OCDF & 26.07 & 442 & 379 & 30 & 444 & 381 & 30 \\
\hline
\end{tabular}

${ }^{a}$ ISS, internal standards (EPA-1613ISS). 


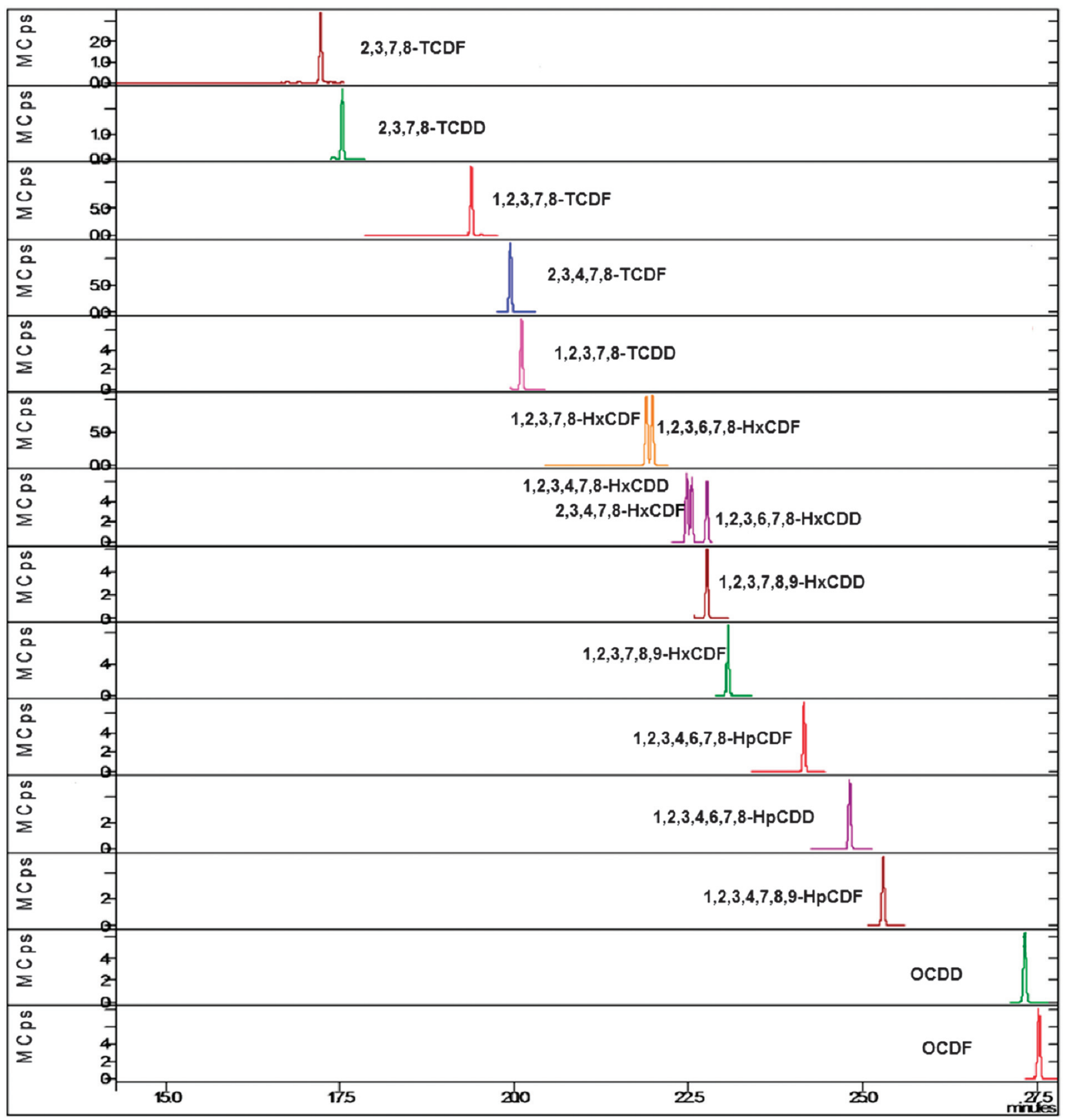

Figure 2. Chromatographic and mass spectrometric separation of 17 polychlorinated dibenzo-p-dioxins (PCDDs) and polychlorinated dibenzofurans (PCDFs) using gas chromatography-triple quadrupole mass spectrometry (GC-MS/MS)

Table 3. Linearity of calibration curves and relative response factors (RRFs) of PCDD/F congeners

\begin{tabular}{lcccc}
\hline Congeners & $\begin{array}{c}\text { Concentration } \\
\text { range }(\mathrm{pg} / \mu \mathrm{L})\end{array}$ & $R^{2}$ & $\begin{array}{c}\text { Average } \\
\text { RRF }\end{array}$ & $\begin{array}{c}\text { RRF\% } \\
\text { RSD }\end{array}$ \\
\hline $2,3,7,8-\mathrm{TCDF}$ & $0.5-40$ & 0.9994 & 1.23 & 8.2 \\
$2,3,7,8-\mathrm{TCDD}$ & $0.5-40$ & 0.9997 & 1.16 & 3.8 \\
$1,2,3,7,8-\mathrm{PeCDF}$ & $2.5-1000$ & 0.9999 & 1.28 & 2.9 \\
$2,3,4,7,8-\mathrm{PeCDF}$ & $2.5-1000$ & 0.9990 & 1.52 & 1.5 \\
$1,2,3,7,8-\mathrm{PeCDD}$ & $2.5-1000$ & 0.9999 & 0.81 & 9.4 \\
$1,2,3,4,7,8-\mathrm{HxCDF}$ & $2.5-1000$ & 0.9991 & 1.38 & 8.5 \\
$1,2,3,6,7,8-\mathrm{HxCDF}$ & $2.5-1000$ & 0.9999 & 1.22 & 3.6 \\
$2,3,4,6,7,8-\mathrm{HxCDF}$ & $2.5-1000$ & 0.9996 & 1.03 & 5.2 \\
$1,2,3,4,7,8-\mathrm{HxCDD}$ & $2.5-1000$ & 0.9994 & 1.27 & 5.8 \\
$1,2,3,6,7,8-\mathrm{HxCDD}$ & $2.5-1000$ & 0.9999 & 0.95 & 4.7 \\
$1,2,3,7,8,9-\mathrm{HxCDD}$ & $2.5-1000$ & 0.9992 & 1.14 & 10.2 \\
$1,2,3,7,8,9-\mathrm{HxCDF}$ & $2.5-1000$ & 0.9999 & 1.09 & 9.4 \\
$1,2,3,4,6,7,8-\mathrm{HpCDF}$ & $2.5-1000$ & 0.9995 & 0.91 & 2.5 \\
$1,2,3,4,6,7,8-\mathrm{HpCDD}$ & $2.5-1000$ & 0.9999 & 1.22 & 4.8 \\
$1,2,3,4,7,8,9-\mathrm{HpCDF}$ & $2.5-1000$ & 0.9991 & 1.05 & 3.8 \\
OCDD & $5.0-2000$ & 0.9999 & 1.34 & 2.4 \\
OCDF & $5.0-2000$ & 0.9999 & 1.25 & 7.2 \\
\hline
\end{tabular}

$103.12 \%$ (average $=95 \%)$, respectively, which was satisfactory ( $>90 \%$ for most congeners) according to US Environmental Protection Agency (EPA) 1613 [14] and European Union (EU) Regulation 709/2014 [26]. These results indicate that $\mathrm{GC}-\mathrm{MS} / \mathrm{MS}$ approaches were suitable for the monitoring of dioxins in soil and comparable in terms of sensitivity to $\mathrm{HRGC/HRMS}$.

\section{Conclusion}

Analysis of dioxins in environmental samples is generally performed by HRGC coupled to HRMS. However, we demonstrate that a GC-MS/MS analysis could be used as an alternative method, thanks to the recent technical advances in MS. In this study, a GC-MS/MS-based analytical method was developed to detect low concentrations of dioxins in soil. The method was validated according to the US EPA Method 1613 and EU Regulations 709/2014 guidelines using EPA-1613 standard solution. The results were satisfactory in terms of 
Table 4. Calibration curve data and instrumental limits of quantitation (iLOQ) values

\begin{tabular}{|c|c|c|c|c|c|c|c|c|}
\hline & $\begin{array}{c}\text { Retention } \\
\text { time (min) }\end{array}$ & $\begin{array}{l}\text { Lowest calibration } \\
\text { point }(\mathrm{pg} / \mu \mathrm{L})\end{array}$ & $\begin{array}{l}\text { Highest calibration } \\
\text { point }(\mathrm{pg} / \mu \mathrm{L})\end{array}$ & $\begin{array}{c}\text { Lowest calibration } \\
\text { point RSD }(\%)\end{array}$ & $\begin{array}{c}R^{2} \text { correlation } \\
\text { coefficient }\end{array}$ & $\begin{array}{c}\text { Difference RF } \\
\text { (low)-RF (All) \% }\end{array}$ & $\begin{array}{c}\text { Average } \\
\text { RF }\end{array}$ & $\begin{array}{c}\text { iLOQ } \\
(\mathrm{pg} / \mu \mathrm{L})\end{array}$ \\
\hline \multicolumn{9}{|l|}{ PCDDs } \\
\hline $2,3,7,8-\mathrm{TCDD}$ & 15.961 & 0.078 & 3.957 & 6.7 & 0.9991 & -0.411 & 2.799 & 0.052 \\
\hline $1,2,3,4,7,8-\mathrm{HxCDD}$ & 21.418 & 0.414 & 20.204 & 8.5 & 0.9999 & 2.170 & 1.436 & 0.350 \\
\hline $1,2,3,6,7,8-\mathrm{HxCDD}$ & 21.425 & 0.394 & 20.067 & 5.7 & 0.9999 & 0.094 & 1.507 & 0.226 \\
\hline $1,2,3,7,8,9-\mathrm{HxCDD}$ & 21.427 & 0.361 & 20.093 & 6.6 & 0.9999 & 1.498 & 1.546 & 0.239 \\
\hline $1,2,3,4,6,7,8-\mathrm{HpCDD}$ & 23.750 & 0.391 & 19.995 & 5.1 & 0.9999 & 1.008 & 1.408 & 0.199 \\
\hline \multicolumn{9}{|l|}{ PCDFs } \\
\hline $2,3,7,8-\mathrm{TCDF}$ & 15.652 & 0.090 & 3.957 & 9.6 & 0.9995 & -16.286 & 5.554 & 0.086 \\
\hline $1,2,3,7,8-\mathrm{PeCDF}$ & 17.879 & 0.427 & 19.929 & 3.2 & 0.9998 & -0.392 & 2.799 & 0.137 \\
\hline $2,3,4,7,8-\mathrm{PeCDF}$ & 18.482 & 0.394 & 19.957 & 3.9 & 0.9997 & -0.503 & 3.151 & 0.154 \\
\hline $1,2,3,4,7,8-\mathrm{HxCDF}$ & 20.511 & 0.421 & 19.855 & 7.5 & 0.9999 & 0.869 & 2.926 & 0.317 \\
\hline $1,2,3,6,7,8-\mathrm{HxCDF}$ & 20.596 & 0.423 & 20.086 & 6.1 & 0.9999 & 0.518 & 3.230 & 0.255 \\
\hline $2,3,4,6,7,8-\mathrm{HxCDF}$ & 21.037 & 0.384 & 20.275 & 2.7 & 0.9999 & 1.283 & 3.166 & 0.104 \\
\hline $1,2,3,4,6,7,8-\mathrm{HpCDF}$ & 22.864 & 0.419 & 19.909 & 3.2 & 0.9999 & -0.127 & 1.987 & 0.136 \\
\hline $1,2,3,4,7,8,9-\mathrm{HpCDF}$ & 24.220 & 0.425 & 19.857 & 3.6 & 0.9999 & -0.243 & 1.484 & 0.153 \\
\hline OCDF & 26.349 & 0.849 & 40.157 & 3.7 & 0.9999 & 0.624 & 1.290 & 0.315 \\
\hline
\end{tabular}

Table 5. Results of dioxin concentration analysis in the reference materials BCR 529 and BCR 530

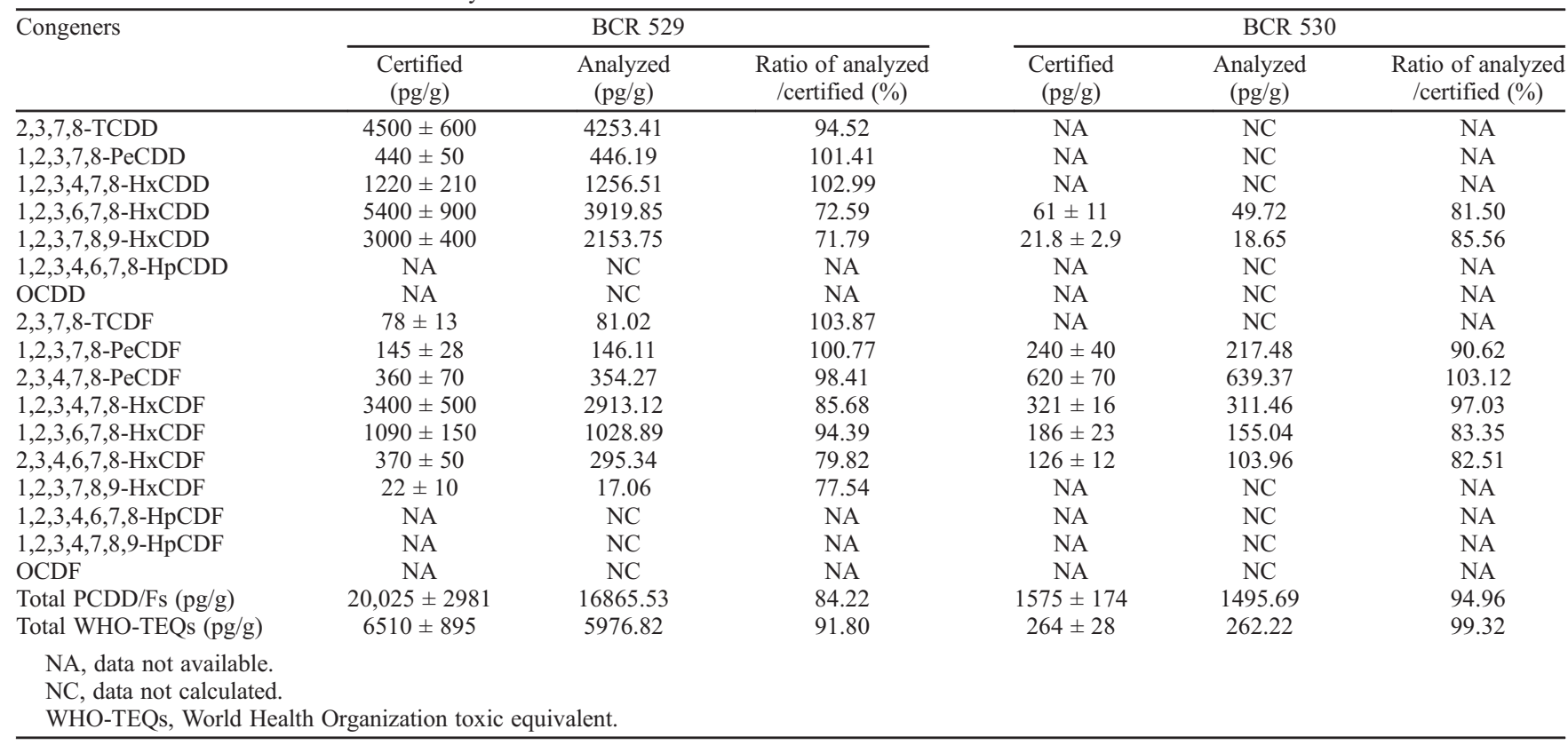

selectivity, linearity of sensitivity, and iLOQ. Furthermore, the accuracy of the analytical method was confirmed using CRMs BCR-529 and BCR-530, and the accuracy was successfully optimized. Thus, GC-MS/MS provides an alternative method for routine screening and quantification of dioxins in soil.

Acknowledgements. We thank to the following people for the critical reading and constructive suggestions: Yong-Seol Choi from BJC Customs Co., Ltd., Dr. Kae Kyoung Kwon from Korea Institute of Ocean Science and Technology, Republic of Korea, and Dr. Nguyễn Ngọc Sinh from Vietnam Association for Conservation of Nature and Environment (VACNE), Vietnam.

\section{References}

1. Nording, M.; Nichkova, M.; Spinnel, E.; Persson, Y.; Gee, S. J.; Hammock, B. D.; Haglund, P. Anal. Bioanal. Chem. 2006, 385, 357-366.

2. Birnbaum, L.; Bosveld, B. T. C.; Brunström, B.; Cook, P.; Feeley, M.; Giesy, J. P.; Hanberg, A.; Hasegawa, R.; Kennedy, S. W.; Kubiak, T.; Larsen, J. C.; vanLeeuwen, F. X. R.; Liem, A. K. D.; Nolt, C.; Peterson, R. E.; Poellinger, L.; Safe, S.; Schrenk, D.; Tillitt, D.; Tysklind, M.; Younes, M.; Waern, F.; Zacharewski, T. Environ. Health Perspect. 2006, 106, 755-792.
3. Do, L.; Lundstedt, S.; Haglund, P. Chemosphere 2013, 90, 2414-2419. 4. Zheng, G. J.; Leung, A. O. W.; Jiao, L. P.; Wong, M. H. Environ. Int 2008, 34, 1050-1061.

5. Rappe, C. Pure Appl. Chem. 1996, 68, 1781-1789.

6. Stanmore, B. R. Combust. Flame 2004, 136, 398-427.

7. Benedetti, P.; Guerriero, E.; Mosca, S.; Rotatori, M. J. Sep. Sci. 2017 40, 3469-3478

8. Alawi, M. A.; Najjar, A. A.; Khoury, H. N. CLEAN - Soil Air Water 2014, 42, 979-985.

9. Chemicals, UNEP, Central and North East Asia Regional Report, Regionally Based Assessment of Persistent Toxic Substances, United Nations Environment Programme 2002.

10. Abad, E.; Llerena, J. J.; Sauló, J.; Caixach, J.; Rivera, J. Chemosphere 2002, 46, 1435-1441.

11. Reiner, E. J. Mass Spectrom. Rev. 2010, 29, 526-559.

12. Focant, J.; Pirard, C.; Eppe, G. De Pauw, E. J. Chromatogr. A 2005 $1067,265-275$.

13. Hong, J.; Miki, Y.; Honda, K.; Toita, H. Chemosphere 2012, 88, $1287-$ 1291.

14. US, EPA, Method 1613 Revision B. Tetra-through octa-chlorinated dioxins and furans by isotope dilution HRGC/HRMS, EPA 821-B94-0059, US Environmental Protection Agency, Washington, DC 1994

15. Ábalos, M.; Cojocariu, C. I.; Silcock, P.; Roberts, D.; Pemberthy, D. M.; Sauló, J.; Abad, E. Anal. Bioanal. Chem. 2016, 408, 3511-3525.

16. Zhang, H.; Bayen, S.; Kelly, B. Sci. Total Environ. 2015, 523, 219-232.

17. Sánchez-Avila, J.; Tauler, R.; Lacorte, S. Environ. Int. 2012, 46, 50-62.

18. García-Bermejo, Á.; Ábalos, M.; Sauló, J.; Abad, E.; González, M. J.; Gómara, B. Anal. Chim. Acta, 2015, 889, 156-165.

19. Bavel, B.van; Geng, D.; Cherta, L.; Nácher-Mestre, J.; Portolés, T.; Ábalos, M.; Sauló, J.; Abad, E.; Dunstan, J.; Jones, R.; Kotz, A.; Winterhalter, 
H.; Malisch, R.; Traag, W.; Hagberg, J.; Jogsten, I. E.; Beltran, J.; Hernández, F. Anal. Chem. 2015, 87, 9047-9053.

20. Organtini, K. L.; Haimovici, L.; Jobst, K. J.; Reiner, E. J.; Ladak, A.; Stevens, D.; Cochran, J. W.; Dorman, F. L. Anal. Chem. 2015, 87, 7902-7908.

21. Sun, H.; Wang, P.; Li, H.; Li, Y.; Zheng, S.; Matsiko, J.; Hao, Y.; Zhang, W.; Wang, D.; Zhang, Q. Sci. China Chem. 2017, 60, 670-677.

22. Plaza Bolaños, P.; Garrido Frenich, A.; Martínez Vidal, J. L. J. Chromatogr. A 2007, 1167, 9-17.
23. Onwudili, J. A.; Hajizadeh, Y.; Zainal, S.; Upton, J.; Williams, P. T. Talanta 2011, 87, 143-151.

24. Kishida, M.; Maekawa, T.; Bandow, H. Anal. Chim. Acta 2010, 659, 86-193.

25. L'Homme, B.; Scholl, G.; Eppe, G.; Focant, J. F. J. Chromatogr. A 2015, 1376, 149-158.

26. Commission Regulation (EU) No. 709/2014 of 20 June 2014 amending Regulation (EC) No. 152/2009 as regards the determination of the levels of dioxins and polychlorinated biphenyls. 